\title{
Analysis on the Relationship Between Economic Cycle Fluctuation and Enterprise Property Insurance Cycle Fluctuation
}

\author{
Shijing $\mathrm{Li}^{1}$,Chengyi $\mathrm{Pu}^{1, *}$ \\ ${ }^{1}$ The Insurance Institute at the Central University of Finance and Economics, Beijing 102206, China \\ *Corresponding author. Pu Chengyi, Email:pucy@,cufe.edu.cn
}

\begin{abstract}
based on the enterprise property insurance market, from 2003 to 2015 in addition to Hong Kong, Macao and Taiwan regions of 31 provinces, municipalities and autonomous regions of time series, panel data as samples, using fixed effect of multiple regression model to estimate the insurance cycle and economic cycle fluctuation correlation, the results showed that the insurance cycle and the lag phase value of economic cycle is significant positive correlation. The regression results show that the periodic fluctuation of China's economy will have a significant positive impact on the periodic fluctuation of enterprise property insurance, and the cycle of enterprise property insurance is likely to lag behind the economic cycle by about one year, that is, the economic cycle fluctuation is an important reason for the periodic fluctuation of enterprise property insurance market.It enriches the theory of enterprise property insurance demand and the correlation study between insurance cycle fluctuation and macro-economic fluctuation, so as to provide inspiration for the regulatory authorities to forecast the insurance cycle of enterprise property insurance market and carry out counter-cyclical supervision according to the macro-economic forecast.
\end{abstract}

Keywords: Enterprise property insurance, Iinsurance cycle; Economic cycle; Fixed effect multiple regression model

\section{经济周期波动与企业财产保险}

\section{周期波动的关系分析}

\author{
黎诗菁 ${ }^{1}$, 蒲成毅 ${ }^{1}$ \\ 中央财经大学保险学院，北京 102206 \\ *通讯作者. 蒲成毅, 电子邮箱: pucy@cufe.edu.cn \\ 摘要: \\ 关于保险周期与经济周期相关性的研究，过去的文献或基于全行业，或基于产险业、寿险业，但并未对险种 \\ 市场再做进一步细分研究。本文以企业财产保险市场为研究对象, 选取 2003-2015 年除港澳台地区外的 31 \\ 个省、市、自治区的面板数据为样本, 选取宏观经济指标 GDP 的滞后一期值作为自变量, 企业财产保险保费
}


收入作为因变量, 适当加入一些已知的影响企业财产保险需求的控制变量, 并对上述变量中的经济类变量采 用 HP 滤波法剥除趋势成分得到各序列的周期性波动成分，而后采用固定效应多元回归模型对保险周期和经济 周期的相关性宏观效应进行实证分析。我们发现：我国经济的周期性波动会对企业财产保险周期产生显著正 向影响, 且这种影响具有滞后性, 即经济周期的波动是引起企业财产保险市场周期波动的一个重要原因。本 研究进一步深化了我们对企财险需求理论的认识, 进一步揭示了保险周期波动与宏观经济波动的关联性, 进 而为监管部门对企财险市场根据宏观经济预测保险周期、进行逆周期监管提供启示。

关键词：企业财产保险，保险周期，宏观经济周期，宏观效应

\section{1. 引 言}

企业财产保险是我国财产保险中非常重要的一 个险种, 它承保的保险标的是存放在固定地点、出于 相对静止状态的企业财产，既包括企业的固定资产， 又包括企业的流动资产。传统理论认为企业之所以购 买企财险, 是出于化解自身风险的目的, 而后现代金 融理论提出: 借助于企业财产保险, 企业不仅能够有 效控制其破产风险, 提高风险管理水平, 还能缓解委 托一一代理问题，提高企业自身价值。

1980 年我国恢复之前被终止的保险业务, 此后, 作为朝阳产业的整个保险业获得了较高速的持续增 长, 大有欣欣向荣之势。然而与此同时企业财产保险 虽然也得到了重生和迅速发展, 其保费收入基本上始 终保持着增长状态, 但与整个保险业的发展速度相比 却显得动力不足一一企财险保费在财险总保费中所 占的比例除 1997 年因保险公司增多而骤升外, 均处 于下降状态。（如图 1)

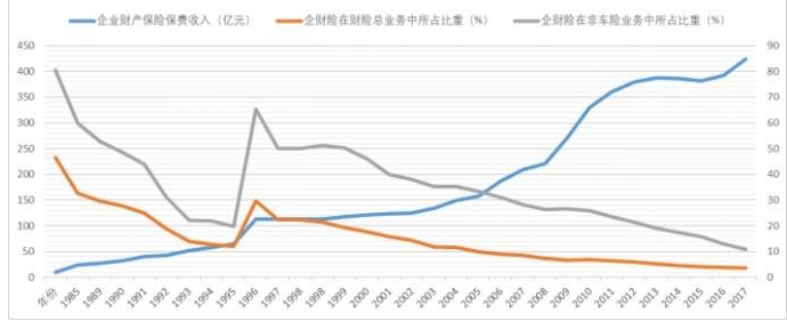

图 1 历年我国企业财产保险业务发展状况

另根据相关统计数据, 从 20 世纪 90 年代至今, 除个别年份外, 我国企业财产保费的增长率基本上总 是低于宏观 GDP 增长率和社会固定资产投资增长率。 因而可知, 企业财产保险可承保的保险标的其实并不 短缺, 从而企业财产保险在财产保险中所占比重之所
以会下滑, 极有可能是因为对于一些应当投保的财产 企业却没有投保。综上，总的来说我国企业财产保险 市场存在的问题是有效需求不足。

基于此发现, 如果保险公司和相关部门能采取措 施激发企业的保险需求，让企业财产保险得到企业的 充分重视，企业更积极地利用企业财产保险控制和化 解风险, 那么就能够使受损企业得到更加充分的经济 补偿和更有效率的资金运用, 使保险公司可以更准确 地控制风险，使我国企业财产保险的发展更上一层楼， 从而使保险业更有效地发挥其经济 “稳定器” 和 “助 动器” 的作用。

目前我国学者已就保险周期和经济周期之间的 关系陆续展开探讨, 他们的实证分析均表明宏观经济 周期波动是引起保险周期波动的重要原因, 这种关系 在保险全行业还是寿险业、产险业均被学者们研究证 实, 本文将在这些研究的基础上将这两大周期的研究 进一步深入企业财产保险这一单一险种市场。

\section{2. 文献综述}

\section{1 经济周期和保险周期的关联相关文献综 述}

近年来, 我国关于保险周期的研究尚处于起步阶 段。

孙祁祥在 2010 年北大赛瑟论坛上首次提出 “保 险周期” 的概念, 并将其定义为 “围绕保险业长期增 长趋势重复出现的周期性波动”。

紧接着, 关于我国与其他国家经济周期和保险周 期的联系, 有的学者对比我国及其他工业化国家与新 
兴市场国家后发现我国保险周期的特征、决定因素以 及和经济周期的联系与其他国家有所不同, 提出目前 我国保险研究应以 “保险周期” 为重点（孙祁祥等,

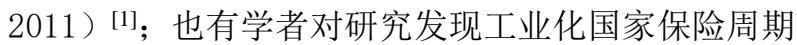
与新兴市场国家的保险周期存在传导机制上的差异 （姚奕、王云龙等，2019）[2]。

此后, 许多学者陆续以中国的自己的保险市场为 背景研究经济周期和保险周期的关联性。

对宏观经济波动可能引致保险周期的内在原因: 有学者作理论分析, 认为宏观经济波动向保险周期波 动的传导机制有两个: 一、通过经济指标 (如银行利 率、 $\mathrm{CPI}$ 、股价指数、货币供给量等) 的变动直接实 现; 二、受到心理预期的强力干预 (熊海帆等, 2011) ${ }^{[3]}$; 亦有学者用保险公司层面的微观面板数据对几个 主流理论假说一一已有损失经验模型、承保能力约束 模型和一般经济因素模型加以实证检验 (姚奕、王云 龙等，2019）[2]。

对宏观经济周期和保险周期相关联的宏观效应: 张玉春等（2016） ${ }^{[4]}$ 采用 HP 滤波法和简单移动平均 法, 探究我国这两大周期的定量关系, 对比这两大周 期的循环波动形态差异, 发现: 我国保险周期不仅受 宏观经济周期影响，同时也受保险业自身产业政策显 著影响, 总体而言保险业周期波动顺周期滞后于 GDP 波动约 1 年左右; 李小林等 (2020) ${ }^{[5]}$ 在上述文献的 基础上采用月度数据, 首次运用 Morlet 小波分析法, 发现: 保险周期和经济周期的平均长度均为 3-4 年, 其中保险周期的长度有缩短趋势且保险周期的波动 较经济周期更为剧烈; 经济周期是引起保险周期波动 的重要原因, 但在金融危机后保险周期反过来对实体 经济的周期性波动产生正向影响; 保险周期和经济周 期之间的关联会受利率和股价波动的显著影响。同时， 他们均分别对全行业、寿险市场和产险市场进行研究 分析, 得出一致结论: 寿险和产险市场受宏观经济变 量周期波动的影响并不一致, 在影响强度和影响时滞 上表现出明显差异。

从上述文献我们可以得出结论: 总体而言, 保险 业周期波动顺周期滞后于经济周期波动约 1 年左右, 经济周期是引起保险周期的重要原因。然而, 他们均
未对分险种市场作进一步细分，既然产险市场和保险 市场整体的周期波动与经济周期之间的关联特征表 现出明显差异, 那么产险市场中的第二大险种一一企 业财产保险的保险周期和产险市场整体，或和保险市 场整体与经济周期的关联是否会表现出高度相似或 明显差异呢? 这一问题的研究将更好的指导监管部 门对分险种市场的监管工作，也将进一步加深我们对 保险周期与经济周期的认识。

\section{2 企业财产保险需求理论相关文献综述}

关于影响企业财产保险需求的因素, 学术界存在 两种主流理论-一传统风险规避理论和现代金融理 论。

刘钢和赵军伟 (2008) ${ }^{[6]}$ 提出企业财产保险的传 统风险规避理论, 认为保险最基本、最主要的职能 分散风险和补偿损失，这也是企业参与保险的最直 接、最主要动机。企业所处的行业环境和自然地理 环境、可作为保险标的的财产数量影响企业所面临 的潜在风险以及损失程度，从而可能影响企业的财 产保险需求。

Zou 和 Adams（2008） [7,8]则坚持企业财产保险的 现代公司金融理论，他们认为现代企业的 “委托一一 代理” 问题耶是引发企业的财产保险需求的一个非常 重要的因素, 表现为管理者与股东、管理者与债权人 之间的博亦。目前，现代金融理论成为解释公司保险 行为的主流经济学思想。

在上述基础上，我们将宏观经济波动纳入企业财 产保险的需求理论中进行分析。

\section{3. 经济周期波动与企业财产保险保险周期波 动关联性的实证分析}

\section{1 变量选取与数据说明}

\section{1 .1 自变量、因变量}

对经济周期波动的测度, 我们选取 GDP 为主要衡 量指标，对企业财产保险周期波动的测度，我们选取 企业财产保险的保费收入为衡量指标，记为 CID，该 指标同样可以用来衡量企业财产保险的需求。 


\section{1 .2 控制变量}

保险周期受货币市场、股票市场、汇率市场的影 响, 可由利率、股指和汇率指标衡量, 但由于研究的 是地区面板数据, 这些因素在地区间无明显差异, 可 纳入地区的固定效应中考虑, 而不用单独作为控制变 量。

基于企业财产保险需求的传统风险规避理论和 现代金融理论，根据国内外文献的实证分析，结合统 计数据的可得性, 影响宏观企业财产保险需求且可作 为控制变量纳入模型中的因素主要有 (以下数据均暂 未做任何处理）：（1）固定资产投资, 用固定资产投 资总额 INVO 表示; （2）风险水平，本文选用地区企 业财产保险赔款支出 (记为 PAYO) 这一指标量化一个 地区的风险水平; (3) 企业所得税, 企业购买保险往 往有避税效应 (Zou and Adams, 2006; Regan and Hur,

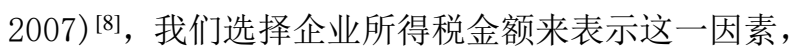
记为 TAX0；（4）教育水平, 选取大专以上人口占总 人口的比重（记为 EDU）来代表教育水平;（5）金融 机构贷款, 选择年末金融机构各项贷款余额这一指标 来表征, 记为 LOAN0;（6）企业规模, Hoyt 和 Khang （2000） [9]等的实证研究结果均显示企业的保险需求 与企业规模负相关我们采用规模以上工业企业单位 数来反映一个地区的企业规模水平, 记为 SIZE。

\subsection{3. 数据来源}

本文样本数据为 2003-2015 年除港澳台外的 31 个省、市、自治区的地区面板数据。数据来源于国家 统计局官网、2004-2016 年《中国保险年鉴》、EPS 数 据库和 CSMAR 数据库。

\section{2 数据处理和模型确定}

3.2.1 对自变量、因变量、经济类控制变量的去 势处理

传统时间序列分析方法认为, 经济波动通常包含 四种因素, 即长期趋势、周期循环波动、随机扰动和 季节波动, 其中只有循环波动因素才能真正体现行业 整体波动的周期性, 保险业周期波动也不例外。但由
于本文使用的是年度数据, 不用考虑季节波动成分, 所以为了更有针对性的测度周期循环波动, 必须剔除 时间序列中的趋势成分及随机波动。除此之外，影响 企业财产保险需求的经济类控制变量均包含一定的 趋势成分。因此, 我们需要对上述变量中的经济变量 GDP、INVO、PAYO、TAXO、LOANO 用 HP 滤波法剔除趋 势因素和随机扰动, 得到周期成分, 记为自变量经济 波动 Macro、控制变量 INV、PAY、TAX、LOAN。

特别地，根据已有文献对保险周期和经济周期关 联性的研究，保险周期整体上顺周期滞后于宏观经济 周期约一年左右, 宏观经济周期波动是影响保险业周 期波动的重要原因。因此本文为了研究该滞后影响在 企业财产保险市场是否也存在, 则应将自变量, 即衡 量保险周期的指标 Macro 取滞后一期值 L_Macro 进 行分析。

\subsection{2 数据的描述性说明分析}

本文使用的是 2003-2015 年的数据, 解释变量取 滞后一期值后 2003 年对应数据缺失, 因此本文用于 模型的数据共有 366 个观察对象, 是时间跨度为 12 年（2004-2015 年）、面板数为 31（对应 31 个省、 直辖市、自治区）的时间序列面板数据。

研究数据的描述性统计显示, 不同年度、不同地 区的经济波动性可能差别很大, 可能为正 (经济向好), 也可能为负（经济下行），部分年度地区的经济波动 性非常大，而部分年度地区的经济波动性又很小。同 时我们还发现, 表征企业规模的 SIZE 标准差非常大, 最大值与最小值相差甚远, 且其取值恒为正数, 因此 为了消除量纲差异，我们对企业规模衡量指标 SIZE 作对数化处理得到 $1 n \_S I Z E$ 进行后续分析。

\section{2 .3 多重共线性检验和相关系数分析}

为了确定包含上述所有解释变量和控制变量的 多元线性回归模型是否存在多重共线性问题，我们在 stata 中进行 VIF 检验, 其结果显示该模型的平均 VIF 值为较小的 1.52 , 即不存在明显的多重共线性问题。 同样的, 通过对解释变量和控制变量的相关系数分析 (如表 1) 我们可以发现模型中除因变量外的各变量 
间相关系数都不大，最大不超过 0.7 , 与 VIF 检验的 结论一致, 模型不存在明显多重共线性问题, 无需剔 除任何变量。

所以最终确定回归模型的形式为式（1）:

INS $=\beta_{0}+\beta_{1}$ Macro $+\beta_{2} I N V+\beta_{3} P A Y+\beta_{4} T A X+\beta_{5} E D U+\beta_{6} L O A N+\beta_{7} \operatorname{In} \_$SIZE $+\epsilon$

\subsubsection{Hausman 检验}

处于同一行业环境和自然地理环境的企业可能 存在一定的关联, 这种关联可能会影响企业的财产保 险需求, 即企业的个体效应可能与其他解释变量相关, 但这是否存在这种相关性是不确定的, 仍需进一步检 验。

因此, 本文将采用 Hausman 检验验证个体效应与 其他解释变量是否相关, 将之作为进行固定效应模型 和随机效应模型篮选的依据。当 Hausman 的原假设 （即个体效应与其他解释变量不相关）成立时, 应当 选择随机效应模型; 当拒绝原假设时, 则应选择固定 效应模型。Hausman 检验结果显示: $\operatorname{chi} 2(4)=14.78$, Prob $>$ chi $2=0.0052$ 。P 值小于 0.01 , 表明在 $1 \%$ 的显 著性水平上拒绝原假设, 因此固定效应模型模型对本 文所选取数据的拟合效果更优。

\section{2 .5 异方差检验}

在确定了使用固定效应模型后, 进行的相应的异 方差检验结果显示为： chi2 $(25)=6650.16$, Prob $>$ chi2 $=0.0000$, 拒绝了不存在异方差的原假设, 说明需要回归的数据存在明显的异方差。为了修正异 方差, 需要在回归模型中结合使用稳健标准差。

\section{3 实证回归结果分析}

使用固定效应模型结合稳健标准误进行回归后， 回归结果如表 1 所示。表征宏观经济波动的变量滞后 一期值 L_Macro 的系数为正且 $\mathrm{p}$ 值小于 0.01 , 这表 明宏观经济的周期波动对企业财产保险周期波动的 影响在 99\%的置信水平上是正相关、显著的，即宏观 经济周期波动导致企业财产保险周期波动的重要原
因，保险周期大概顺周期滞后于经济周期一年。该结 论与之前某些学者研究整个保险行业周期的结果一 致。

表 1 多元回归分析结果

\begin{tabular}{ccccc}
\hline 变量 & 系数 & 稳健标准误 & $t$ 统计量 & $p$ 值 \\
\hline L_Macro & $0.0348 * * *$ & 0.0121 & 2.88 & 0.008 \\
INV & -0.0021 & 0.0088 & -0.24 & 0.816 \\
PAY & -0.0312 & 0.0275 & -1.14 & 0.267 \\
TAX & 0.1175 & 0.1317 & 0.89 & 0.381 \\
EDU & $7.913 * * *$ & 1.661 & 4.76 & 0.000 \\
& & & & \\
LOAN & $-0.0053 * *$ & 0.0022 & -2.40 & -0.025 \\
& & & & \\
Ln_SIZE & $-60.56 *$ & 30.95 & -1.96 & 0.062 \\
& & & & \\
& $\mathrm{~F}(7,24)=6.38$ & Prob $>\mathrm{F}=00.0003$ & \\
\hline
\end{tabular}

除此之外我们还得到了控制变量与企财险需求 的相关关系, 但因与本文研究内容无关, 在此不进行 赘述。

\section{4. 结论及建议}

\section{1 结论}

本文结合国内外已有关于保险周期和经济周期 关联性以及对企业财产保险需求的研究, 将保险周期 与经济周期的关联性研究进一步拓展到企业财产保 险市场，选取宏观经济指标 GDP 的周期性波动成分滞 后一期值为自变量, 选取企业财产保险保费收入的周 期性波动成分为因变量, 加入若干控制变量, 以 31 个 省、直辖市、自治区 2003-2015 年的相关面板数据为 样本进行分析，对企业财产保险市场中两大周期的相 关关系进行实证研究。结果显示: 宏观经济波动的滞 后一期值确实对企业财产保险的保费收入波动产生 明显正效应，即宏观经济周期波动是导致企业财产保 险周期波动的重要原因, 其保险周期大概顺周期滞后 
于经济周期一年。该结论与之前某些学者研究整个保 险行业周期的结论一致。

\section{2 对监管部门的决策建议}

该研究结果不仅在理论上丰富了保险周期和经 济周期的关联性研究以及企业财产保险需求理论研 究, 而且对监管部门针对企业财产保险这一市场相机 决策、制定监管政策具有一定的指导意义。

基于上述研究结论, 本文的政策建议如下: 一方 面，监管部门应充分利用宏观经济波动信息合理预判 企业财产保险的保险周期，正确对待其周期波动现象， 提前做好应对措施, 促进企业财产保险的稳定经营和 健康发展; 另一方面应充分利用企业财产保险的保险 周期整体上顺周期滞后于经济周期一年左右的特征, 把握好时机进行逆周期监管, 在经济下行时适当放松 监管力度促进保险发展, 在经济上行时可适当加大监 管力度，稳定保险经营，保护投保人权益。

\section{致谢}

本文是北京高校高精尖学科 “战略经济与军民 融合” 交叉学科（GJJ2019163）、中央财经大学 “一 流学科”建设项目 “巨灾风险管理与自然灾害治理 现代化研究”,2020 年度国家民委民族研究项目 “后 脱贫时代西部藏区乡村振兴风险与内置金融研究 （2020-GMB-030）”的阶段性研究成果。

\section{参考文献}

[1] 孙祁祥, 郑伟, 肖志光. 经济周期与保险周期- 中国案例与国际比较 $[\mathrm{J}]$.数量经济技术经济研究, 2011(3): 3-20.

[2] 姚奕, 王云龙.保险周期的影响因素分析一一基 于全球范围保险公司面板数据的研究 [J].保险研 究, 2019(3):36-47.

[3] 熊海帆, 卓志, 王威明.保险周期存在性的协整模 型检验: 基于中国市场的分析 [J].保险研究, 2011 (6) : $36-42$.
[4] 张玉春, 王雅婷, 万里虹.我国保险周期与经济周 期波动形态对比研究 [J].保险研究，2016（6）: 40-47.

[5] 李小林, 李金金, 刘倩男.我国保险周期与经济周期 的动态关联研究 [J].保险研究，2020(4):16-22.

[6] 刘钢,赵军伟.浙江中小企业财产保险服务调查报 告[J].保险研究,2008(05):89-92.

[7] Hong Zou, Mike B. Adams, and Mike J. Buckle. Corporate Risks and Property Insurance: Evidence from the People's Republic of China[J].The Journal of Risk and Insurance, 2003, 70(2): 289-314.

[8] Hong Zou,Mike B. Adams. The corporate purchase of property insurance: Chinese evidence[J]. Journal of Financial Intermediation,2006,15(2):165-196.

[9] Hoyt, Robert E., and Ho Khang. On the Demand for Corporate Property Insurance[J]. The Journal of Risk and Insurance, 2000,67(1):91 - 107. 